\title{
Rearing of candidate queens by honeybee, Apis mellifera, workers (Hymenoptera: Apidae) is independent of genetic relatedness
}

\author{
Satoshi Koyama, ${ }^{1,2, *}$ Ken-ichi Harano, ${ }^{3}$ Tadao Hirota, ${ }^{4}$ Toshiyuki SatoH ${ }^{1}$ and \\ Yoshiaki OBARA ${ }^{1}$ \\ ${ }^{1}$ United Graduate School of Veterinary Medicine, Gifu, University; Gifu 501-1193, Japan \\ ${ }^{2}$ Department of Veterinary Medicine, Faculty of Agriculture, Tokyo University of Agriculture and Technology; Fuchu, Tokyo \\ 183-8509, Japan \\ ${ }^{3}$ Faculty of Agriculture, Tamagawa University; Machida, Tokyo 194-8610, Japan \\ ${ }^{4}$ Department of Biology, Faculty of Science, Yamagata University; Yamagata 990-8560, Japan
}

(Received 9 March 2006; Accepted 16 May 2007)

\begin{abstract}
Polyandry in honeybee queens (Apis mellifera) leads to many subfamilies within a colony. Nepotism is expected to occur under these circumstances since honeybee workers can increase their inclusive fitness by favoring full-sisters over half-sisters. The potential benefits of nepotism to workers may be most apparent in queen rearing in which workers can readily influence the genetic composition of the next generation. To determine whether the kin-selected nepotism hypothesis could explain queen rearing, observations were made on the care behavior exhibited by workers toward queen larvae in 4 colonies, and patrilines were identified using DNA microsatellite markers. We observed 521 worker visitation behaviors directed towards queen larvae during $101 \mathrm{~h}$ of observation. Care behaviors were found to occur independently of the genetic relatedness between nurse bees and nursed queen larvae. We therefore suggest that the kin-selected nepotism hypothesis cannot explain queen rearing.
\end{abstract}

Key words: Honeybee; Apis mellifera; nepotism; 'royalty’ allele; queen rearing

\section{INTRODUCTION}

It is known that the queens of some eusocial Hymenoptera mate with a single male while others mate with multiple males (Boomsma and Ratnieks, 1996; Strassmann, 2001). Honeybee queens (Apis mellifera) exhibit extreme polyandry, typically mating with between 7 and 20 males (Estoup et al., 1994). The sperm from different males is mixed and used for fertilization (Sasaki et al., 1995; Haberl and Tautz, 1998). Variable paternity is predicted to result in a conflict of interest among workers, and may manifest in the form of nepotistic behavior towards individuals from the same patriline. This idea led to investigations on nepotism that mainly focused on queen rearing by workers (Tarpy et al., 2004).

When a queen dies or is removed, some larvae and/or eggs are selected as new candidate queens to be fed royal jelly. It has been reported that only a few emerge as new queens in a colony, despite relatively many candidates being reared (Winston, 1987). In these situations, conflicts occur between the multiple queens. Queens that have already emerged will kill the remaining candidate queens, and when two or more candidate queens emerge simultaneously, violent duels result in a single survivor (Huber, 1792; Gilley, 2001). Workers are thought to play a nepotistic role during the queenrearing phase by investing more resources in rearing those queen larvae that are genetically more closely related to them.

Noonan (1986) reported evidence of this proposed nepotism by using two phenotypic markers to show that workers preferentially visited queen cells containing larvae of their own subfamily; however, this work was criticized because the colonies contained only two subfamilies, a condi-

\footnotetext{
* To whom correspondence should be addressed at: E-mail: skoyama@cc.tuat.ac.jp
} DOI: $10.1303 /$ aez.2007.541 
tion that rarely occurs in nature, and because there was no control of the recessive cuticular marker (Breed et al., 1994). Page et al. (1989) conducted a similar study but identified subfamilies using malate dehydrogenase allozymes instead of phenotypic markers. Again, workers were found to be significantly more associated with candidate queens that were more closely related to them. This study met with criticism from Oldroyd et al. (1990), who pointed out a systematic flaw in the statistical methods used; however, the data were later independently reanalyzed and found to support the kin-selected nepotism theory (Visscher, 1998). Significant differences between the subfamily proportions of nurse bees and worker larval populations suggested that nurse bees were not random samples of the worker population. It also seemed that candidate queens were not randomly chosen from eggs and/or larvae and that nurse bees associated more intimately with more closely related queens. More recently, evidence from hybrid European and Africanized honeybee colonies suggested that workers exhibited a kin preference in queen cell visitations (Schneider and DeGrandiHoffman, 2002), although this finding was not upheld in a naturally mated colony (Châline and Arnold, 2005).

Evidence of nepotism in natural honeybee colony is elusive; however, to our knowledge, there is only one observational study (Châline and Arnold, 2005) of queen-rearing behavior of nurse bees in a naturally mated colony. Châline and Arnold (2005) used only one colony and observed each queen cell for just $30 \mathrm{~min}$ daily, resulting in rather few feeding behaviors being observed per worker. In the present study, we examined whether queen-rearing behaviors observed in honeybee workers could adequately be explained by the kinselected nepotism hypothesis. Workers were painted with a colored identification mark and observed as they directed care behavior to candidate queen larvae. Genetic relatedness between workers and candidate queens was assessed using DNA microsatellite markers. Under the kin-selected nepotism hypothesis, workers should invest more in the rearing of full-sister larvae than half-sister larvae. This preference may be reflected in an increased frequency of care behavior and/or care duration towards full-sisters.

\section{MATERIALS AND METHODS}

Source colonies. Four source colonies were chosen from an apiary in Tokyo University of Agriculture and Technology, Tokyo, Japan, and used to set up experimental colonies (Fig. 1). It was later discovered that colony 1 contained workers from two different queens as it had been established by colony fission approximately 20 days previously (the workers were therefore either daughters of the new queen or full-sisters or half-sisters of the new queen). We confirmed that workers were either daughters or sisters of the new queen and were part of the swarm that established the new colony. Colony 1 was therefore excluded from our analysis of full-sister preference. The other colonies were each derived from a single queen.

Experimental colonies. Source colonies were divided into 'queenright' and 'queenless' colonies. Queenless colonies were left without further treatment for a week prior to the destruction of all queen cells. Twenty newly hatched larvae were then transferred from queenright colonies to queenless colonies. The larvae were singly grafted into artificial queen cups attached to two horizontal bars according to Laidlaw (1979), but using water instead of royal jelly, since Visscher (1998) suggested that royal jelly might obscure the cue enabling subfamily discrimination. In colony 2 , only 7 out of 20 artificial cells were accepted by the queenless colony.

Observational colonies. Two brood combs (containing all immature stages) and approximately 2,000 workers were selected from each of the queenright colonies and introduced into glasswalled observation hives. The following day, 10 queen cells containing grafted queen larvae were removed from the queenless colony and attached to the bottom quarter of the combs in the observation

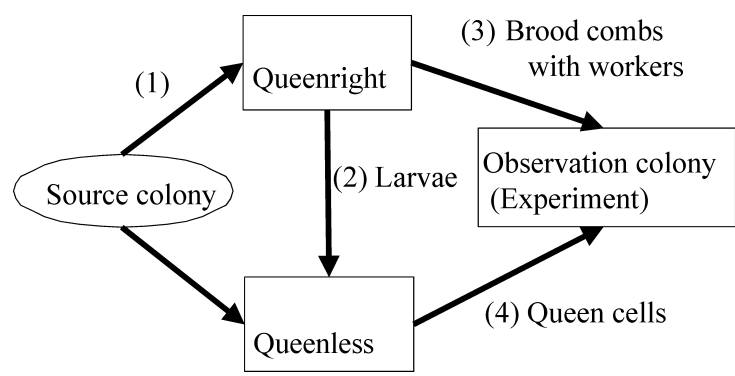

Fig. 1. Procedure of colony establishment. 
colony. Approximately 50 workers observed to be rearing queen larvae were then collected, marked with paint on the dorsal part of their abdomens, and returned to the colony.

Behavioral observation. The behavior of workers was observed during their visitations to queen cells. We measured both the frequency and duration of visitations to different queen cells. Workers were assumed to care for the queen larvae in the artificial cells they visited, although the precise nature of their visitation behavior is not known; however, we believed it was suitable candidate behavior in which to look for nepotism. Observations were carried out for 6-10 h daily, until a queen cell was capped. Following the termination of observations, we collected both painted workers and the larvae in the queen cells. These samples were stored at $-80^{\circ} \mathrm{C}$ until DNA extraction. Some queen larvae were killed during the observation period and therefore excluded from all further analysis. Some larvae were killed after the observation period and, although providing useful observational data, could obviously not be subjected to genetic analysis.

Genetic analysis. We extracted DNA with Chelex 100 resin (Walsh et al., 1991) and amplified four microsatellite loci (A7, A14, A88, and A107; Estoup et al., 1994; Solignac et al., 2003) using a polymerase chain reaction (PCR) with a standard protocol. PCR was carried out in a $20 \mu \mathrm{l}$ total reaction mixture, containing $1 \mu 1 \mathrm{DNA}$ extract, $1 \times$ reaction buffer, $20 \mu \mathrm{M}$ of each dNTP, $2.0 \mathrm{mM} \mathrm{MgCl}_{2}$, $400 \mathrm{~nm}$ of each primer, and $0.5 \mathrm{U}$ Taq polymerase. The reactions were: initial denaturation at $94^{\circ} \mathrm{C}$ for $1 \mathrm{~min}$, followed by 30 cycles of denaturation $(30 \mathrm{~s}$ at $\left.94^{\circ} \mathrm{C}\right)$, annealing $(30 \mathrm{~s}$ at the annealing temperature for each primers- $\mathrm{A} 7, \mathrm{~A} 107,58^{\circ} \mathrm{C} ; \mathrm{A} 14$, $\left.55^{\circ} \mathrm{C} ; \mathrm{A} 88,48^{\circ} \mathrm{C}\right)$, and extension $\left(30 \mathrm{~s}\right.$ at $\left.72^{\circ} \mathrm{C}\right)$; PCR products were then stored at $4{ }^{\circ} \mathrm{C}$. PCR products were viewed using electrophoresis on a $4 \%$ urea-acrylamide gel in an ABI 377 DNA sequencer, and genotyped with an ABI 377 Gene$\mathrm{Scan}^{\mathrm{TM}}$. We determined a patriline of each individual in experimental colonies following Estoup et al. (1994). The probability (non-detection error) of two males in a population having identical genotypes at all loci analyzed, and thus having indistinguishable offspring is:

$$
d_{p}=\prod\left(\sum q_{i}^{2}\right) j
$$

where $q_{i}$ denotes allele frequencies at each $j$ locus (Boomsma and Ratnieks, 1996). We also calculated mean relatedness within each colony using Relatedness 5.0.8 (Queller and Goodnight, 1989).

Statistical analysis. We performed the Friedman test to assess the significance of difference in the relative frequency of care behavior toward each larva against the null hypothesis that all larvae would receive equal care from workers. A generalized linear mixed model (GLMM) was used to examine whether workers visited full-sister queen larvae more frequently than half-sister queen larvae. Calculations were performed using the lme4 (Bates and Sarkar, 2006) and Matrix (Bates and Maechler, 2006) package in R. In this analysis, both the frequency and duration of a worker attending a queen cell were set to dependent variables. The frequency of visitation was assumed to be Poisson distributed. Whether a worker visited a full-sister or half-sister was set to a dichotomic independent variable. The identities of workers and queen cells were included as random factors because the same workers and queen cells were observed repeatedly. The identities of colonies were also included as random factors because the data of three different colonies were analyzed simultaneously. The Laplace approximation method and maximization of the restricted log-likelihood (REML) were used in the lmer function (lme4 package).

\section{RESULTS}

\section{Visitation behavior}

We monitored 37 candidate queens and marked 233 workers for observations. Thirty-one of the 37 candidates survived the observational period, and the data obtained were analyzed (Table 1). A total of 521 visitation behaviors exhibited by 149 of the 233 paint-marked workers were recorded during $101 \mathrm{~h}$ of observation. The time spent by workers in visiting candidate queens ranged widely from 1 to $179 \mathrm{~s}$ (frequency range: $1-17$, mean duration $=20.67 \mathrm{~s}$ ). Analysis revealed a significant difference among larvae in the frequency of visitation by workers in colonies 3 and 4 (Friedman test, $p=0.04, p=0.004$ respectively, Table 2), marginal significance in colony $2(p=0.07)$, but no significance in colony 1 , which involved workers from two queens $(p>0.5)$. 
Table 1. Observations of workers and queen larval populations in the four experimental colonies

\begin{tabular}{|c|c|c|c|c|c|c|c|}
\hline & \multirow{2}{*}{ Obs. date } & \multirow{2}{*}{ Obs. hours } & \multicolumn{2}{|c|}{ Number of workers sampled } & \multicolumn{3}{|c|}{ Number of queen larvae sampled } \\
\hline & & & Marked & Genotyped & Grafted & Survived & Genotyped \\
\hline Colony 1 & June $11-13$ & 26 & 50 & 30 & 10 & 10 & 9 \\
\hline Colony 2 & July 30-Aug. 1 & 19 & 49 & 29 & 7 & 7 & 6 \\
\hline Colony 3 & Sept. 24-26 & 29 & 60 & 47 & 10 & 9 & 7 \\
\hline Colony 4 & Oct. $16-18$ & 27 & 74 & 61 & 10 & 5 & 5 \\
\hline Total & & 101 & 233 & 167 & 37 & 31 & 27 \\
\hline
\end{tabular}

Table 2. Difference in visitation rates among queen larvae (analyzed using the Friedman test)

\begin{tabular}{lcccc}
\hline & \multicolumn{4}{c}{ Difference in visitation } \\
\cline { 2 - 5 } & $N_{\text {worker }}$ & Fr & df & $p$ \\
\hline Colony 1 & 32 & 7.62 & 9 & 0.57 \\
Colony 2 & 37 & 11.55 & 6 & 0.07 \\
Colony 3 & 54 & 17.65 & 9 & 0.04 \\
Colony 4 & 26 & 15.12 & 4 & 0.004 \\
\hline
\end{tabular}

\section{Genetic analysis}

A hundred and thirty-seven workers and 18 queen larvae from colonies 2, 3 and 4 were distributed to each patriline based on DNA microsatellite data (Table 3) to determine whether visitation behaviors to queen larvae by workers were associated with relatedness. The remaining workers and candidate queens could not be genotyped and were excluded from genetic analysis. Seventy workers shared a father drone with one or more queen larvae within the experiment. The non-detection error of the population was 0.003 , which had little effect on the results. We failed to detect a significant difference in visitation duration toward full-sister and half-sister queen larvae. ANOVA did not show a statistical difference between models with and without kinship among workers and queens as an independent variable $\left(\chi^{2}=0.80, \mathrm{df}=1, p=0.37\right.$, Fig. 2). This applied both to total visitation frequency and to total visitation duration of each worker $\left(\chi^{2}=0.02, \mathrm{df}=1, p=0.89 ; \chi^{2}=0.43, \mathrm{df}=1\right.$, $p=0.51$ respectively, Fig. 3). Once a worker entered a queen cell, it was impossible to accurately determine what activity it is performing, so it was very difficult to determine whether workers were actually caring for queen larvae throughout their visitation to queen cells; however, worker behavior might vary with respect to time spent in the queen cell and our observations showed that a significant number of visitations occurred within $5 \mathrm{~s}$ (162 out of 521). Thus, we postulated that visitations in which duration exceeded $5 \mathrm{~s}$ involve some queen care (also see Schneider and DeGrandi-Hoffman, 2002). In addition, workers might perform cell inspections for up to $20 \mathrm{~s}$ (Winston, 1987). We therefore only looked for evidence of kin preference when duration exceeded either $5 \mathrm{~s}$ or $20 \mathrm{~s}$. For both analyses, we failed to find a significant preference for more closely related queen larvae (for more than $5 \mathrm{~s}, p>0.45$; for more than $20 \mathrm{~s}, p>0.46$ ).

\section{DISCUSSION}

Our investigations revealed that the amount of investment in each queen larva by workers is independent of the genetic relatedness of workers and larvae. This is consistent with the results of studies that used naturally mated colonies and found no evidence of nepotism (e.g., Gilley, 2003; Châline and Arnold, 2005; Châline et al., 2005), but not with studies where artificially established colonies were used (e.g., Noonan, 1986; Page et al., 1989).

Honeybees endowed with kin recognition ability might be nepotistic towards their kin either agonistically, increasing colony fitness, or antagonistically, entailing costs for a colony. Antagonistic behavior in queen-rearing workers involves killing, removing, or eating a larva in a queen cell. If any of these antagonistic behaviors are exhibited by a worker, it will result in the death of the larva and may therefore be costly to the colony. Nepotism may also manifest itself as agonistic behavior. Agonistic behavior in queen-rearing workers involves feeding queen larvae or incubating queen cells. The visitation behaviors observed in this experi- 
Table 3. Microsatellite analysis data and mean relatedness within a colony

\begin{tabular}{|c|c|c|c|c|c|c|c|}
\hline & \multicolumn{4}{|c|}{ Number of alleles detected within } & \multirow{3}{*}{ Patriline $^{\mathrm{a}}$} & \multirow{3}{*}{$R( \pm \mathrm{SE})^{\mathrm{b}}$} & \multirow{3}{*}{$R$ from patriline } \\
\hline & \multicolumn{4}{|c|}{ Loci } & & & \\
\hline & A 88 & A7 & A14 & A107 & & & \\
\hline Colony 1 & 5 & 8 & 5 & 12 & - & $0.21 \pm 0.13$ & - \\
\hline Colony 2 & 3 & 7 & 5 & 13 & 15 & $0.26 \pm 0.03$ & 0.28 \\
\hline Colony 3 & 2 & 5 & 4 & 8 & 8 & $0.28 \pm 0.08$ & 0.31 \\
\hline Colony 4 & 5 & 6 & 3 & 6 & 9 & $0.29 \pm 0.06$ & 0.31 \\
\hline
\end{tabular}

${ }^{\text {a }}$ Number of patrilines within a colony based on DNA microsatellite data. Colony 1 contained workers from two queens.

${ }^{\mathrm{b}}$ Mean relatedness within a colony and standard error by jackknife resampling technique calculated with Relatedness 5.0.

${ }^{\mathrm{c}}$ Mean relatedness within colony calculated from the number of patrilines, assuming workers from each patriline contribute to their colony equally.

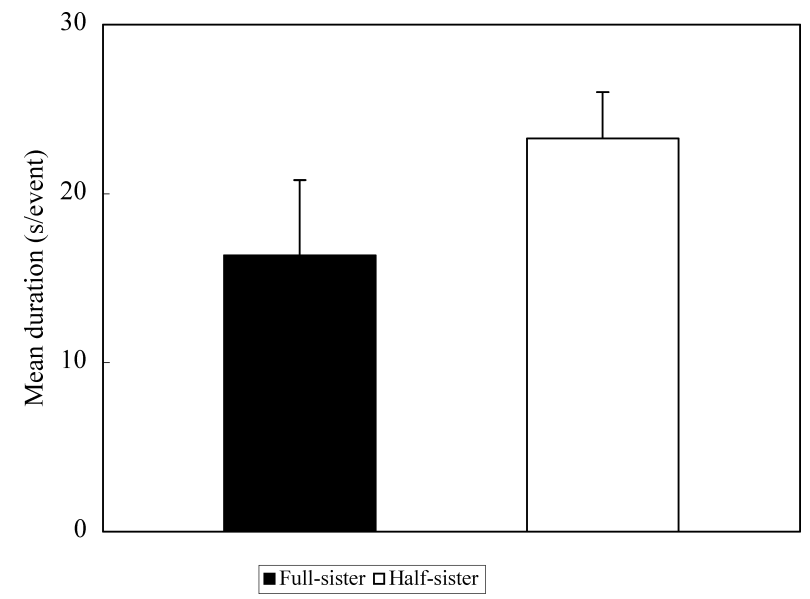

Fig. 2. Duration of care by workers of full-sisters and half-sisters. Twenty-one and 132 care behaviors towards fullsister and half-sister larvae were pooled respectively from three colonies. No significant preference for full-sisters was found. Error bars indicate SE.

ment are believed to be agonistic in nature and involve the care of queen larvae. As such, it would seem that this behavior might be a likely candidate for the evolution of nepotism; however, the results presented here do not support the kin-selected nepotism hypothesis for queen rearing.

An alternative to the kin-selected nepotism hypothesis has been proposed by Tilley and Oldroyd (1997), who demonstrated, using DNA microsatellites, that certain subfamilies of candidate queens were disproportionately over-represented relative to the worker brood. Based on these results, they proposed the 'royalty' allele hypothesis (Osborne and Oldroyd, 1999), which predicts that larvae from a particular subfamily should preferentially be reared as queens by workers, due to the possession of cer-
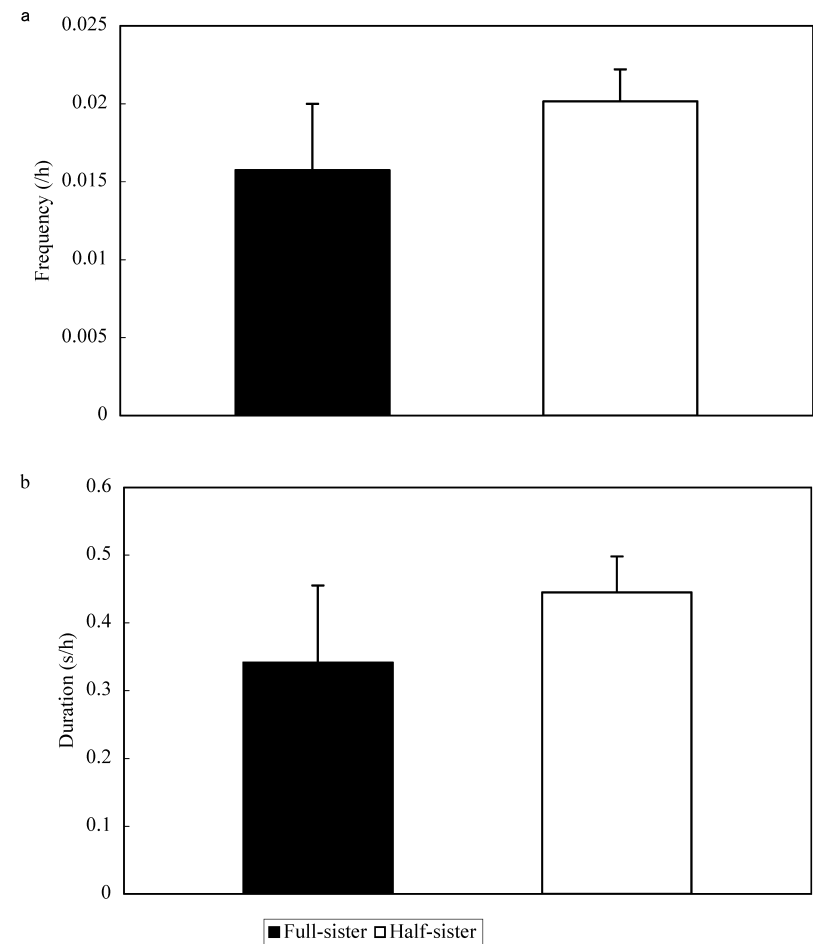

Fig. 3. Total care investment by each worker toward fullsisters and half-sisters. No significant preference for full-sisters was found in care investment indicators: a, care frequency and $b$, total care duration. Seventy worker samples from three colonies were pooled. Care frequency (a) and duration (b) were divided by observation time and number of fullsister/half-sister queen larvae built in the observation colony. Error bars indicate SE.

tain alleles. Our results, shown in Table 2, revealed that the frequency of care behavior toward each queen larva differed in colonies 3 and 4, seemingly agreeing with the hypothesis; however, this was not the case in colony 1 , which suggests that no particular larvae were preferentially reared in this colony. 
It should be remembered, however, that colony 1 contained workers from two queens, a situation which is uncommon in the wild. These observations are consistent with the results of Osborne and Oldroyd (1999). They found higher levels of subfamily heterogeneity in candidate queens when the brood to be reared as queens was in a mother colony than when the brood was introduced into unrelated colonies. They concluded that the royalty allele hypothesis could not adequately explain their findings. Although further studies need to be conducted, the royalty allele hypothesis seems unlikely to explain queen rearing.

In this study, the outcome of replicate experiments showed some variation. For example, the numbers of surviving larvae differed between replicates. There are a number of possible explanations for this, the most likely being seasonal change, as this is well known to affect queen rearing activity. In this study, we failed to observe nepotism under the conditions imposed in the experimental colonies. Our results are essentially consistent with those of Mohammedi and Le Conte (2000), who found no evidence of nepotism in queen rearing in their experimental colonies in either spring or winter. Our study supports previous findings that nepotism in queen rearing is probably absent or weakly expressed (Tarpy et al., 2004). We hope that future study will determine the criteria used by workers in selecting broods as queens, and which larvae are preferentially reared as candidate queens.

\section{ACKNOWLEDGEMENTS}

We thank our colleagues at Tokyo University of Agriculture and Technology for their helpful suggestions during the course of this work. We are grateful to Remy Ware and Michael Majerus for suggestions on the final draft. We also thank the referees for their valuable comments. This study was supported by a Grant-in-Aid for Scientific Research from the Ministry of Education, Culture, Sports, Science and Technology of Japan to TS (No. 08740595). This work was also supported in part by a Grant-in-Aid for COE Research (E-1) from the Ministry of Education, Culture, Sports, Science and Technology of Japan and the Tokyu Foundation for Better Environment (No. 2003-30).

\section{REFERENCES}

Bates, D. and M. Maechler (2006) Matrix: A Matrix package for R. R package version 0.9975-5.

Bates, D. and D. Sarkar (2006) 1me4: Linear mixed-effects models using S4 classes. R package version 0.9975-8.

Boomsma, J. J. and F. L. W. Ratnieks (1996) Paternity in eusocial Hymenoptera. Philos. Trans. R. Soc. Lond. B
351: 947-975.

Breed, M. D., C. K. Welchand and R. C. Cruz (1994) Kin discrimination within honey bee (Apis mellifera) colonies: an analysis of the evidence. Behav. Proc. 33: 25-40.

Châline, N. and G. Arnold (2005) A scientific note on the lack of nepotism in queen larval feeding during emergency queen rearing in a naturally mated honey bee colony. Apidologie 36: 141-142.

Châline, N., S. J. Martin and F. L. W. Ratnieks (2005) Absence of nepotism toward imprisoned young queens during swarming in the honey bee. Behav. Ecol. 16: 403-409.

Estoup, A., M. Solignac and J.-M. Cornuet (1994) Precise assessment of the number of patrilines and of genetic relatedness in honeybee colonies. Proc. R. Soc. Lond. B 258: $1-7$.

Gilley, D. C. (2001) The behavior of honey bees (Apis mellifera ligustica) colonies during queen duels. Ethology 107: 601-622.

Gilley, D. C. (2003) Absence of nepotism in the harassment of dueling queens by honeybee workers. Proc. R. Soc. Lond. B 270: 2045-2049.

Haberl, M. and D. Tautz (1998) Sperm usage in honey bees. Behav. Ecol. Sociobiol. 42: 247-255.

Huber, F. (1792) New Observations on Bees. Dadant, Hamilton, IL.

Laidlaw, H. H. (1979) Contemporary Queen Rearing. Dadant, Hamilton, IL. 199 pp.

Mohammedi, A. and Y. Le Conte (2000) Do environmental conditions exert an effect on nest-mate recognition in queen rearing honey bees? Insectes Soc. 47: 307-312.

Noonan, K. C. (1986) Recognition of queen larvae by worker honey bees (Apis mellifera). Ethology 73: 295-306.

Oldroyd, B. P., T. E. Rinderer and S. M. Buco (1990) Nepotism in the honey bee. Nature 346: 707-708.

Osborne, K. E. and B. P. Oldroyd (1999) Possible causes of reproductive dominance during emergency queen rearing by honeybees. Anim. Behav. 58: 267-272.

Page, R. E., G. E. Robinson and M. K. Fondrk (1989) Genetic specialists, kin recognition and nepotism in honey bee colonies. Nature 338: 576-579.

Queller, D. C. and K. F. Goodnight (1989) Estimating relatedness using genetic markers. Evolution 43(2): $258-275$.

Sasaki, K., T. Satoh and Y. Obara (1995) Sperm utilization by honey bee queens: DNA fingerprinting analysis. Appl. Entomol. Zool. 30: 335-341.

Schneider, S. S. and G. DeGrandi-Hoffman (2002) The influence of worker behavior and paternity on the development and emergence of honey bee queens. Insectes Soc. 49: 306-314.

Solignac, M., D. Vautrin, F. Mougel, E. Baudry, A. Estoup, L. Garnery, G. Haberl and J.-M. Counuet (2003) Five hundred and fifty microsatellite markers for the study of the honeybee (Apis mellifera L.) genome. Mol. Ecol. Notes 3: 307-311.

Strassmann, J. E. (2001) The rarity of multiple mating by fe- 
males in the social Hymenoptera. Insectes Soc. 48: $1-13$.

Tarpy, D. R., D. C. Gilley and T. D. Seeley (2004) Levels of selection in a social insect: a review of conflict and cooperation during honey bee (Apis mellifera) queen replacement. Behav. Ecol. Sociobiol. 55: 513-523.

Tilley, C. A. and B. P. Oldroyd (1997) Unequal subfamily proportions among honey bee queen and worker brood. Anim. Behav. 54: 1483-1490.
Visscher, P. K. (1998) Colony integration and reproductive conflict in honey bees. Apidologie 29: 23-45.

Walsh, P. S., D. A. Metzger and R. Higuchi (1991) Chelex (R)100 as a medium for simple extraction of DNA for PCR-based typing from forensic material. Biotechniques 10: 507.

Winston, M. L. (1987) The Biology of the Honey Bee. Harvard University Press, Cambridge, Mass. $281 \mathrm{pp}$. 